\title{
The Study of the Logistics Management Information System based on Android
}

\author{
Zhihai LIU ${ }^{\mathrm{a}}$, Dandan ZHANG ${ }^{\mathrm{b}}$, Ronghua ZHANG ${ }^{\mathrm{s}}$, Kaidi YANG ${ }^{\mathrm{d}}$ \\ Shandong University of Science and Technology, Qingdao 266590, China;

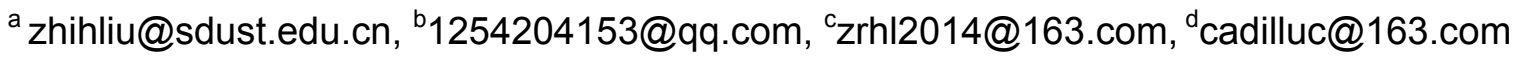

Keywords: Logistics management system; Android; Vehicle scheduling; ant colony algorithm

\begin{abstract}
Starting from the actual demand of logistics enterprise information management, vehicle scheduling problem model was established and the solving method of model was found based on the ant colony algorithm. At the same time, based on Android and MySQL database development environment, the paper carried on the system requirements and functional analysis, database design, interface design, etc. The system overcomes the limitations of other management information systems, improves the management efficiency, realizes the flexibility, intelligence and digital of information management, and provides a new platform for enterprise logistics information management.
\end{abstract}

\section{Introduction}

With the development of social economy, logistics has become an important industry of China's economic development, and logistics management information system plays an essential role in the logistics industry. In the aspects of the logistics management information construction, professional software development and logistics management information systems, the United States are in the world leading level ${ }^{[1]}$. And European Union countries also focus on the development some mature, practical strong, dedicated logistics information software ${ }^{[2]}$. Compared with abroad, our country's logistics informatization level is lower than Europe and the United States national informatization level. The logistics management information system not only combines the comprehensive advantages of the Android platform, but also makes the whole logistics process more optimized and efficient. It plays a great role in promoting the construction of digital and intelligent logistics management information system.

\section{The key technology of system}

\subsection{System architecture model}

The system uses the hybrid architecture of $\mathrm{C} / \mathrm{S}$ and $\mathrm{B} / \mathrm{S} .{ }^{[3]}$ The hybrid architecture can integrate the advantages of $\mathrm{C} / \mathrm{S}$ and $\mathrm{B} / \mathrm{S}$. Based on the advantages of $\mathrm{C} / \mathrm{S}$ and $\mathrm{B} / \mathrm{S}$, the logistics management information system has the characteristics of specificity, sealing ability, and has the advantages of generality, openness. The hybrid architecture of $\mathrm{C} / \mathrm{S}$ and $\mathrm{B} / \mathrm{S}$ can make the enterprise internal users and the external users access the internal interface and the external interface respectively, give full play to the respective advantages of $\mathrm{C} / \mathrm{S}$ and $\mathrm{B} / \mathrm{S}$, in order to adapt to the increasingly complex operating environment and needs.

\subsection{Android operating system}

Logistics management information system is developed in a software development kit for Android4.4.2, the Eclipse integrated development environment, java can be used to write cross platform application software for object-oriented programming. Java is the remarkable versatility, high efficiency, portability and security platform.

\subsection{MYSQL database}

Logistics management information system based on Android, data storage needs large amount of information, in order to guarantee the security of data, data storage are done by the server. The Android's built-in SQLite embedded database is very small and the function is not very perfect. Thus the choice of the database is not SQLite database, but the MySQL database. The MySQL 
database changes the database tables through stored procedures indirectly, and update the new data information timely, which makes the collected data has the characteristics of safety, convenience and real-time performance.

\section{Vehicle scheduling problem based on ant colony algorithm}

In the process of the whole logistics operation, vehicle scheduling is the core link, the main way to control the transportation cost of logistics enterprises is the optimization of vehicle dispatching scheme. The solving of vehicle scheduling problem usually use ant colony algorithm. The principle of ant colony algorithm is a kind of positive feedback parallel mechanism, inspired by the collective foraging behavior of ants. In this paper, the ant colony algorithm is applied to the logistics vehicle scheduling problem. The mathematical model ${ }^{[4]}$ is established by this principle, and the optimal solution is found by the model.

\subsection{The establishment of the model}

Logistics enterprises from the distribution center $\mathrm{P}_{0}$ using dispatch vehicles to $\mathrm{N}$ customers receiving point $\mathrm{V}_{\mathrm{i}}(\mathrm{i}=1,2, \ldots, \mathrm{N})$ delivery goods, enterprises have $\mathrm{M}$ vehicles can be scheduled, and sent $\mathrm{m}$ car loading $\mathrm{n}$ receiving point and towards $\mathrm{n}$ receiving orders for goods delivery, then back to the distribution center $\mathrm{P}_{0}$. And delivery tasks must be completed on the same day.

$$
\begin{gathered}
\text { Objective function: } \left.\min Z=\sum_{m=1}^{M} \sum_{i=1}^{n_{m}} \mid y_{m i} \sum_{j=1}^{n_{m}} X_{m, i j} l_{i, j}\right\rfloor \\
\sum_{i=1}^{n_{m}} q\left(i_{m}\right)<Q_{m} \\
\sum_{m=1}^{M} n_{m}=n \\
\sum_{m=1}^{M} y_{m i}=1 \\
\sum_{i, j=0}^{N} x_{m, i j}=\sum_{i=0}^{N} y_{m i} \\
0 \leq n_{m} \leq n \\
x_{m, i j}=\left\{\begin{array}{c}
1, \text { dispatch vehicles from i to } j ; i, j \in V \\
0, \text { otherwise }
\end{array}\right. \\
y_{m i}=\left\{\begin{array}{c}
1, \text { receiving point } V_{i} \text { by the } m \text { vehicle distribution; } ; \in V \\
0, \text { otherwise }
\end{array}\right.
\end{gathered}
$$

Among them , $\mathrm{n}_{\mathrm{m}}$ - the first $\mathrm{m}$ cars in total distribution $\mathrm{n}_{\mathrm{m}}$ goods; $\mathrm{q}(\mathrm{i})$ - receiving point Vi the weight of the goods in order to be delivery, $\mathrm{i}=1,2, \ldots, \mathrm{N} ; \mathrm{Q}_{\mathrm{m}}$ - the load of a delivery vehicle for the $\mathrm{M}, \mathrm{m}=1,2, \ldots, \mathrm{M} ; \mathrm{x}_{\mathrm{m}, \mathrm{ij}}$ - distribution vehicle $\mathrm{m}$ in receiving point after $\mathrm{i}$ and $\mathrm{j} ; \mathrm{y}_{\mathrm{mi}}$-vehicle $\mathrm{m}$ delivery orders for goods of receiving point $\mathrm{Vi}$.

\subsection{The solution of the model}

According to the above model, the use of ant colony algorithm, the method ${ }^{[5]}$ mainly includes determining the number of ant colony, setting the path selection rules and pheromone-updating mechanism.

(1) Determine the number of ant colony. Ant colony with $\mathrm{M}$ only ants on the $\mathrm{P}_{0}$ to carry out the food, there are $\mathrm{N}$ foraging sites. In time $\mathrm{t}$, the number of ants in the receiving point $\mathrm{V}_{\mathrm{i}}$ is expressed as $m=\sum N n m_{i}(t)$.

(2) Set the path selection rules. In the process of feeding, the route is determined by the pheromone concentration and the total length of the path. At a certain time $t, \mathrm{P}^{\mathrm{m}_{\mathrm{ij}}}(\mathrm{t})$ is the probability of ant $\mathrm{m}$ from the receiving point $\mathrm{V}_{\mathrm{i}}$ selection to receiving point $\mathrm{V}_{\mathrm{j}}$.

$$
P_{i j}^{m}(t)=\left\{\begin{array}{c}
\frac{\tau_{i j}^{\alpha}(t) \times \eta_{i j}^{\beta}(t)}{\sum_{r \notin a b U_{m}} \tau_{i r}^{\alpha}(t) \times \eta_{i r}^{\beta}(t)}, j \notin t a b U_{m} \\
0, \text { otherwise }
\end{array}\right.
$$

Among them, $\tau_{i j}(t)$-at $t$ time, ant route between receiving point $V_{i}$ and $V_{j}$ secretion of pheromone concentration; $\eta_{i j}$-the expectation of ants from receiving point $V_{i}$ to $V_{j} ; \alpha$-the importance degree of 
pheromone concentration while the ants choose a receiving point as the next destination, $0 \leq \alpha \leq 1 ; \beta$ selectivity factor weight, $0 \leq \beta \leq 1$; tabU $\mathrm{m}_{\mathrm{m}}$-a tabU list of ant $\mathrm{m}$ after receiving point.

(3) Set pheromone-updating mechanism. In the process of ant colony algorithm, when all ants have completed a search process, the relevant information will be updated in time. At the same time, it also needs to follow a certain rule in the process of pheromone updating.

$$
\text { Update rules: }\left\{\begin{array}{c}
\tau_{i j}(t+n)=(1-\rho) \times \tau_{i j}(t)+\Delta \tau_{i j}, 0<\rho<1 \\
\Delta \tau_{i j}=\sum_{m=1}^{M} \Delta \tau_{i}^{m}
\end{array}\right.
$$

Among them, $\Delta \tau_{\mathrm{ij}}$-after the completion of a "feeding" search process, the amount of pheromone between the receiving point $\mathrm{V}_{\mathrm{i}}$ to $\mathrm{V}_{\mathrm{j}}$; $\mathrm{L}_{\mathrm{k}}$-the total path length of the ants; $\mathrm{Q}$ is a constant.

\section{System design and implementation}

\subsection{Requirement and feature analysis}

Logistics management information system mainly covers the goods order management, vehicle scheduling management, inventory management, personnel information management and information system settings modules. Commodity management involves commodity information query, modification, addition, deletion and other operations, order management, including increase of customer order, order maintenance, new order review management, order contract management and order audit management. Order audit management mainly makes the corresponding processing through the order information; vehicle scheduling management includes vehicle management, team management and scheduling management, scheduling management takes some measures such as Vehicle scheduling or LCL scheduling, scheduling maintenance and scheduling audits according to the size of the order; inventory information management includes inventory management, warehouse-out management and warehouse management. Staff management and announcement information constitute the personnel information management module, mainly dealing with personnel information. System Settings can be used for password change and permissions settings, permissions settings of loading is in accordance with the "users-roles-permissions-page" configuration of the structure of four layers, it improves the security of the management.

Data Flow Diagram (Data Flow Diagram, DFD) is a graphic representation for the working process from the "Data" and "Data processing", it only describes the information flow in the system and processing situation, does not reflect physical parts in the system. Both users and software personnel can understand easily. Logistics management information system based on Android data flow belongs to the transformation of data flow. The system data flow diagram is shown in figure1.

\section{2 database design}

Database design includes concept design, logical structure design and physical structure design. The goal of conceptual structure design is to generate database concept structure of information requirement of the reaction organization, in other words, conceptual model. Conceptual model is independent of the DBMS and the structure of the computer hardware. In the logic structure design, the main task is to convert the Entity-relationship diagram to specific DBMS data model, namely the relational model.

The database created for the system is called logisticsinfo, the structure of tables are created according to the structure of the database model after the logistics management information system finished. There would be many tables in logistics management information system, such as a registered customer table, administrator information table, warehouse information table, etc.

\subsection{System implementation}

The main interface mainly includes five plates: goods order management, vehicle scheduling management, inventory management, personnel information management, information system 
setting. A mouse click can shows various operations. Order management interface is shown in figure 2 .

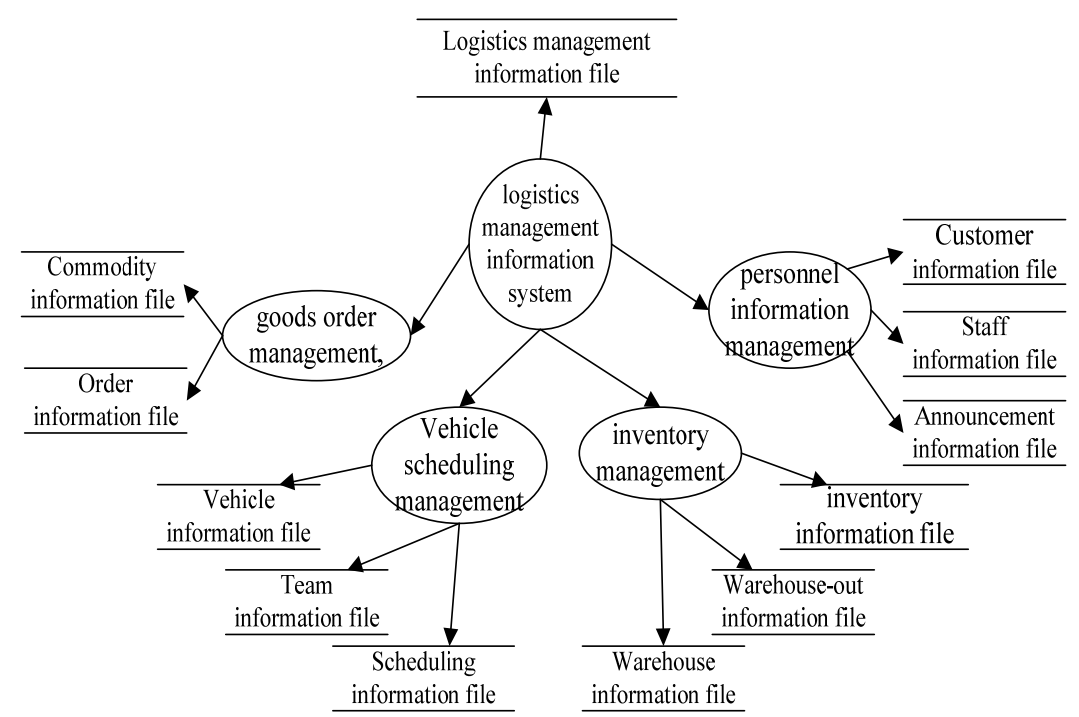

Fig. 1 Data flow diagram

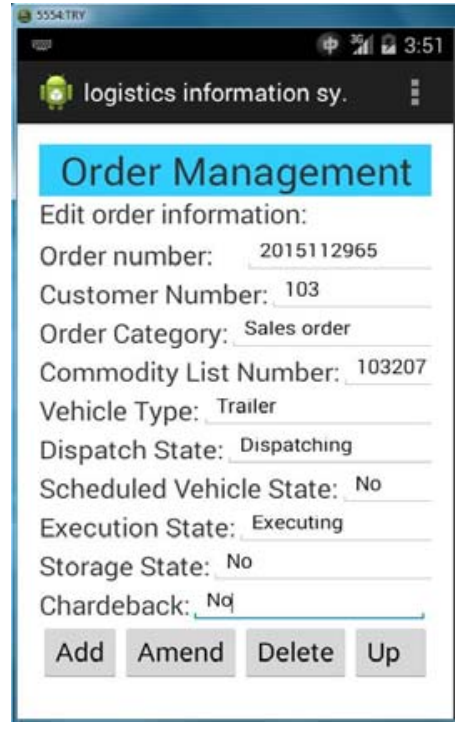

Fig. 2 Order management interface

\section{Conclusion}

In the process of the whole logistics operation, vehicle scheduling is the core link, vehicle scheduling problem model was established and the solving method of model was found based on the ant colony algorithm. In the development process of the logistics management information system, based on the Eclipse integrated development environment, the JAVA programming language and Navicat for MySQL database, the paper carried on the system requirements and functional analysis, database design, interface design, etc. The paper made the corresponding system function diagram, data flow diagram, E-R diagram and the data table, etc. Logistics management information system passes the security, stability and function test operation. The model and system in the enterprise information management has a certain practical application value, improve the enterprise management efficiency. However, there are still many problems in the model and system, and it needs to be improved in the following work.

\section{Acknowledgement}

The paper is sponsored by National Natural Science Foundation of China (Grant No. 51375282), and Special funds for cultivation of Taishan Scholars.

\section{References}

[1] Du Zhandong. Logistics management information system based on intelligent mobile phone platform [D]. Beijing: Beijing university of posts and telecommunications, 2013:1-12.

[2] Wang Tao. Logistics information management system for WEB service [D]. Chengdu: University of Electronic Science and Technology of China, 2013:1-11.

[3] Liu Yongqing. Research on logistics system architecture based on integration of 3-tier C /S and 3-tier B /S [J]. Journal of Hunan University of Science \& Technology (Natural Science Edition), 2005(3):86-89.

[4] Gong Genping. Research and design of management information system for the third party logistics [D]. Nanchang: Nanchang University, 2013.

[5] Zhang Wei. Research on the problem of the vehicle logistics distribution path optimization based on ant colony algorithm [J]. Logistics Sci-Tech, 2015(10):48-60. 